\title{
Multiple Factors Converge to Influence Women's Persistence in Computing: A Qualitative Analysis of Persisters and Nonpersisters
}

\author{
Wendy DuBow and Joanna Weidler-Lewis \\ National Center for Women \& IT \\ University of Colorado \\ Boulder, CO, USA \\ wendy.dubow@colorado.edu \\ weidlerl@colorado.edu
}

\author{
Alexis Kaminsky \\ Kaminsky Consulting, LLC \\ Albuquerque, New Mexico, USA \\ alexis.kaminsky@gmail.com
}

\begin{abstract}
Previous research has suggested that access and exposure to computing, social supports, preparatory privilege, a sense of belonging in computing and/or a computing identity all contribute to women pursuing computing as a field of study or intended career. What we know less about is what keeps young women persisting in computing despite the obstacles they encounter. This paper describes findings from analysis of 64 in-depth interviews with young women who in high school expressed interest in computing by looking into NCWIT's Aspirations in Computing Award. The dataset includes Award winners and nonwinners, some of whom have persisted in computing and some who have not. Our findings suggest that multiple, redundant supports, including community reinforcement, as well as a bolstered sense of identity/belonging, may make the difference in who persists and who does not.
\end{abstract}

Keywords-gender; broadening participation; supportive factors; preparatory privilege; persistence; psychosocial factors, social issues, social and behavioral sciences

\section{BACKGROUND}

Many individuals and organizations have been working tirelessly for years on the issues of how to recruit and retain more women and other historically under-represented individuals in the field of computer science. Much has been learned in recent years about practices that may work to interest and retain these individuals. We know now that early exposure, access to rigorous computing classes, and having friends who also do computing are important for stimulating students' interest in the field.

What we know less about is what makes some women persist and others not in the face of field-wide obstacles, such as computer science not being a graduation requirement in high school, male-dominated classes at most high schools and colleges, unhelpful stereotypes and media images, subtle and outright biases from teachers, counselors, and even fellow students. In the face of all of this, how do some women persist? It is this question that we set out to answer in our study comparing NCWIT Aspirations in Computing Award winners and women who had expressed interest in computing during high school, but then did not win the award, or did not even apply.

\section{LITERATURE REVIEW}

Empirical research has exploded the myth that the reason for the gender gap in computing is because girls are simply less interested in computing than boys [1-3]. Early access and exposure to computing experiences can spark interest in computing for girls and boys alike. Equally well-established, though, is the fact that youth have different degrees of access to and experience with computing. Research has shown patterns of inequity - of access and experience - based on gender, race, socio-economic status, geographic location, primary language, and (dis)ability [1-8].

\section{A. Early Access and Exposure}

Margolis and Fisher offer a compelling description of social factors such as family expectations, peer groups, and consumer choices that come together to stimulate a nascent technology identity. For boys, these factors often converge to reinforce stereotypes that boys are "magnetically attracted" to computing [3]. For girls, the story is somewhat different. There are girls who, with their parents (usually their dads), take computers apart and put them back together for fun and who have peer groups that do computing-related activities together such as robotics. For some girls, however, these early experiences do not coalesce into a seamless narrative of who they are, partly because they conflict with dominant narratives about what girls should like and do [9].

While exposure is necessary for sparking interest, it does not inevitably lead to young women sticking with computing. Indeed, one study found that early exposure did not correlate strongly with young women's decisions to pursue computer science (nor did age of first exposure, access to ipads and smart phones, "natural ability," and pre-college computer science curriculum) [10]. On the other hand, social support, particularly from peers, emerged as one of the key factors associated with a female's decision to major in computer science (along with sense of self-efficacy in computing-related areas such as puzzles, exposure to formal and informal computing science education, and awareness of computer science careers). 


\section{B. Social Support: Peer and Community}

Starting in about middle school, peer groups become particularly influential, as youth look to one another for affirmation and acceptance. Robnett and Leaper's 2012 study on the role of social identity and self-concept in STEM career choices found that the stronger one's identification with a peer group, the more internalized were group norms [11]. The authors concluded, "Belonging to a friendship group that values STEM may help girls overcome negative expectations or prejudices regarding STEM achievement" [11, p.654]. Other research has shown that building supportive networks for girls is critical because youth consider their peers as guides, especially when they lack adult mentors or role models [1213]. Studies also have found that peer support is an important factor in what young women choose to study [14-16].

The community in which young women live has been shown to have a strong influence on their exposure to other females who participate in nontraditional activities such as computing [17]. Another important factor for young women choosing a career is input from people they respect. Young women are significantly more likely than young men to seek input about careers [18]. Therefore, it is important that the community knows to reinforce computing as a viable option.

\section{Preparatory Privilege}

While early computing access and exposure may not predict if an individual pursues computing, preparatory privilege derived from accumulated computing experiencesusually starting at home and propelled by informal computing experiences with friends - sets youth up for success later [2]. This setup makes their transition into being a person who "does computing" appear seamless. Youth from families and communities that are less educated or less able to access outof-school opportunities, for example, struggle not only with acquiring the competencies needed to succeed in computing classes, but also have to navigate socio-cultural and psychological barriers grounded in stereotypes about computer scientists and computing fields, implicit and sometimes explicit biases, isolation, and invisibility [2],[4],[19-20].

\section{Sense of Belonging}

A sense of belonging, or a feeling of "fit," is important for supporting student interest and persistence; this becomes even more critical when we consider the wide variety of girls we would like to attract to computing. Subtle cues like sexist posters or "geeky" paraphernalia in a computer classroom or lab can suggest to girls and women that they don't belong [2122]. Less subtle messages such as teachers, counselors or parents steering female students to non-technical classes convey to young women that technology is not for them, even when they may have an interest or aptitude. Worse, even wellmeaning adults sometimes believe that males have a "natural" talent for computing compared to females [23-26].

\section{E. Developing a Computing Identity}

Drawing from their ethnographic study, Carlone and Johnson (2012) theorize that science identity forms through the interactions of performance (behaving like a scientist) and competence (understanding of content). They further conclude that recognition (being seen by self and others as a scientist) is "a key component of science identity development" [20, p.1197]. It follows, then, that a discipline-based identity cannot develop without others around to reinforce it. Because identity is a fluid construct, borne of affordances and obstacles experienced, and nurtured (or negated) by one's community [4], [19-20], [27], the formative experiences a young woman has can nurture or undermine a nascent computing identity.

\section{MEthodology}

Over a three-year period from 2012 to 2015, 64 women were interviewed either individually via telephone, videoconference or in person, or via videoconference focus group. ${ }^{1}$ These women are all part of a larger mixed methods study currently underway that uses the National Center for Women \& Information Technology (NCWIT) database of winners and nonwinners of the NCWIT Aspirations in Computing (AiC) Award. Anyone who registered on the AiC website between 2009-2013, or had won the award in 2007 or 2008, was eligible to be included in the sample. In 2012, a survey was fielded with this sample, which yielded about 1,500 usable responses. The interview sample was initially constructed from a random sample of the 1,500 survey respondents. As nonwinners proved more difficult to recruit, we expanded our invitations to all of the nonwinners who had completed surveys. Multiple methods were used to contact nonwinners, including emails, texts, phone calls, and emails to parents. In the end, the interview portion of the study included 20 nonwinners and 44 winners.

This study's scope ultimately will include three point-intime surveys, interviews and focus groups, as well as analysis of data gleaned from an online community that the AiC winners can participate in. This paper considers only the extensive interview data; future work will synthesize findings from the other data sources.

All interviews and focus groups followed a similar semistructured protocol, exploring the women's experiences with and perceptions about computing, their sense of belonging or identity relative to computing or engineering, as well as the interaction of their winner/non-winner status on their attitudes and behaviors toward computing. All conversations were recorded and transcribed. Transcripts were uploaded into Dedoose, a cloud-based qualitative analysis program.

We used a semi-emergent approach to content analysis, in which we applied both content-based codes as well as codes that were emergent constructs in our data [29-31]. To facilitate comparisons of qualitative and quantitative data [28], codes were created based on social cognitive career theory (SCCT), since our survey instrument was developed around these theoretical constructs (e.g., outcome expectations, selfefficacy). SCCT examines the interrelated aspects of career development including how career and education interests evolve, how choices are made related to careers and education, and how success is measured and obtained in careers and education [28]. Additional codes such as "belonging" were drawn from themes that emerged in reviews of the literature over the last 40 years and our data [1][27].

\footnotetext{
${ }^{1}$ One interview recording was inaudible, leaving us with 63 usable transcripts.
} 
Supportive factors and inhibiting factors and the women's responses to them were coded in every transcript. These categories were further sub-coded using the five metanarratives that Kanny and her colleagues identified in their research review: individual background characteristics; family influences and expectations; structural barriers and affordances in K-12 education; psychological factors, values, and preferences; and perceptions of STEM fields [1]. We added a sixth sub-code, post-secondary barriers and affordances, because the majority of women who participated in the interview component of our study were in college or working.

During coding and analysis, the research team met regularly to define and refine codes and work toward inter-rater agreement. Each transcript was coded by at least two researchers, and all new sub-codes were reviewed by a second member of the team to ensure they were consistently applied to the data.

\section{RESUlTS}

The women we interviewed were racially and ethnically diverse with the largest proportions being Caucasian/White, Asian/Pacific Islander, and Hispanic/Latina (41\%, 30\%, and $16 \%$, respectively). The remaining women identified as African American/Black (8\%), multi-racial (3\%), and Native American/Alaska Native/American Indian (2\%). The majority of our respondents $(75 \%)$ were in college at the time they were interviewed, five $(8 \%)$ were still in high school, two (3\%) were attending community college, two (3\%) were attending graduate school, and seven $(11 \%)$ had graduated and were in the workforce.

Over three-quarters of the women who participated in the interview portion of our study have persisted in computing. (Persistence in this context is defined as majoring or minoring in computer science or engineering and/or working in a technical computing job after college.) AiC Award winners in our sample were more likely to persist than non-winners, but some non-winners persisted as well (39 of 43 or $91 \%$ of winners vs. 11 of 20 or $55 \%$ of non-winners). In each of the four groups-winner/persister, nonwinner/persister, winner/nonpersister and nonwinner/nonpersister-50\% or more were women who faced "the double bind" [27] of being under-represented in computing due to both gender and race/ethnicity.

Interviews with both $\mathrm{AiC}$ Award winners and nonwinners contained excerpts we coded as "supportive factors" for persisting in computing as well as "inhibiting factors." This was true whether or not the respondents ultimately persisted in computing. We found substantial variation within winner and nonwinner groups as well as persisters and nonpersisters. We learned that both winners and nonwinners encountered supports and challenges along their educational paths through high school and college. Winners, though, tended to talk at greater length and with more examples of supports and inhibitors they experienced relative to computing. One reason for this result is that AiC Award winners, particularly the national Award winners (30 of the 43 winners in our sample) who won the most competitive version of the AiC high school award, are presented with numerous educational and professional opportunities, as well as cohort support, through direct communications from NCWIT and a Facebook group hosted by NCWIT. Persisters-whether or not they were AiC Award winners-discussed more computingrelated experiences overall than nonpersisters, and their interview data contained more supportive factors.

How do we make sense of these patterns? What can we learn from these women's lived experiences? In the pages that follow, we present a series of profiles to put faces to the ways in which supportive (and inhibiting) factors play into women's pursuit of computing. These profiles are presented not as individual cases, but rather as representative of the trends we see in the approximately 60 hours of data we have analyzed. These profiles serve to convey a sense of the breadth of the entire qualitative sample.

In the first profile, the respondent's story demonstrates the supportive forces of family, community, and school structure all working toward her choice of a computer science major. In the second, the respondent's story shows how individual interest and aptitude are not always enough to sustain a pursuit into computing, even when structural affordances are present. Significantly, in the second profile, she has supportive factors, but they are neither pervasive nor redundant.

\section{A. Profile 1: Persisting in Computing}

$\mathrm{Joan}^{2}$, a White woman, grew up in the Pacific Northwest in one of the most dense technology hubs in the U.S. When asked how she became interested in computing, Joan said, "One [reason] is a product of the environment in which I was growing up. All of the kids were like, you know, 'CS is so cool." Another reason was her family:

So my mom's a computer scientist... she always really talked about how cool it is. So my dad's not a computer scientist, but he's always, like, yeah, I need help programming things so can you, please, program this for me? So I just got a lot of experience in general, I think, also hearing both of them talk about [pause], like, not just their jobs, but about the world in general.

Joan had multiple opportunities to engage with computer science through Advanced Placement Computer Science (AP CS) and competitions during high school.

Other than AP CS and that [high school-wide] competition, I did a lot of robotics. So starting in 9th grade, 9th and 12th grade basically did a lot of robotics. Like went to a lot of competitions for that. And there's always a programming aspect to it. And I was the programmer for a couple of those years. Like the main programmer.

Joan had a core group of male and female friends from elementary school that she attended middle and high school with and participated with in out-of-school activities.

A lot of us throughout elementary school and onwards, you know, we'd do, like, math competitions, things of that

\footnotetext{
${ }^{2}$ All names used are pseudonyms to protect respondent
} confidentiality. 
nature. You end up, I mean, yes, some of your friends are girls, but also some of your friends are guys. And I think [it was] that same group of people that we ended up joining robotics with and doing AP computer science with.

On creating a network of support, she noted, "People, like, in my so-called network, like, they exist right next to me. So it's not like I made any effort at all."

She applied once for the AiC Award, and won. Afterward, Joan attended a prestigious university well-known for its gender-balanced CS program. She was double majoring in computer science and international business. Although still in college when we interviewed her, she had already worked for several organizations-small startups, NGOs, and large companies.

\section{B. Profile 2: Not Persisting in Computing}

Sophia, a Latina woman, grew up in California's Central Valley and described her surroundings this way: "My community, they didn't really do much about technology "cause it's more of an agricultural town." Her mother "is a homemaker" and her father "is a dairy cow milker." Sophia explained:

[My parents] were really focused on me getting a higher education because they wanted me to get that since they couldn't get that when they were young 'cause they didn't really know about that. So they tried to, like, get a lot of information on college and how to get me into tutoring. They put me in all these extracurricular activities when I was in junior high... And they convinced me to [take] AP classes, honors classes, and to challenge myself so I could get into a better college.

Sophia attended a public high school that had one elective computing course for 3,000 students, which was taught by the Integrated Engineering teacher. Sophia said this teacher "would give us [girls] more side projects so we'd be more interested because he was worried we'd get out, like, on the second week." He also encouraged her to apply for the AiC award, which she did once, although she did not win. When describing her experience in her computing class, Sophia said:

I really liked it...I liked hands-on things so it was really fun doing all the hands-on projects...And I enjoyed the software. I thought it was interesting... [A]t first I was, like, oh, maybe I want to do something with technology.

But technology was not prevalent in Sophia's life other than the one computing class. She noted:

Everyone pretty much has a job that's kind of agricultural, or there's the lawyers and the doctors. There aren't very many, like, computer people. [And at school], mmm, well, the [computer] class, they didn't, people didn't really know that class existed so they didn't really opinionate about it. 'Cause it was one of the smaller classes that you had to, like, ask about it to even know about it.

Sophia's experience in trying to integrate her interest with technology with her sense of belonging in her community contrasts directly with Joan's experience. Sophia observed:
I mostly found that, like, animal science-wise I was around agricultural more. So I kind of experienced it more and I got to take, like, an animal science class in my high school so I was exposed to that. So I found out, oh, I really like it.... and I want to do medicine or, like, something I can do with animals and I really enjoyed it. And then the fact that all my family is in the Central Valley...it would be easier for me to find a job after I graduate, there, based on if I'm a veterinarian or something based on animal science.

When asked why she didn't pursue CS, Sophia said that she felt she had to choose between computing or veterinary medicine in college because she "couldn't see how to integrate the two."

Joan and Sophia can be seen as existing at almost opposite ends of a computing access continuum. In the second profile, we see clear interest and even exposure to computing. Sophia's school offered both curricular and extra-curricular computing activities. Through that engineering teacher, she did volunteer tech support in her community for older adults. But her exposure to computing was not undergirded by familial understanding or community support for what it meant to be in computer science. Her computing activities were enough to pique her desire to major in CS, but not enough to sustain it. In contrast, Joan's profile, and her persistence in the field, seems almost like a foregone conclusion, even to her. Joan sits squarely on the extreme end of the spectrum with multiple factors supporting her choice and telling her she belongs.

Lest these profiles give the impression that there are two distinct pathways, we include three additional cases that reflect the ways in which a community of support can connect the dots for girls and women who might not otherwise find their way and can help them build their computing identity.

\section{Profiles 3-5: Persisting in Computing Against Odds}

Anvi. An Indian woman, Anvi immigrated to the US with her parents when she was high school age. She had limited support from her parents in the sense that they had no experience with college, with the U.S. educational system, and had not attended college themselves. Also unhelpful, Anvi had a school counselor who treated her like she was "dumb... She recommended that I take Microsoft Office and not introduction to Java...she always underestimated me." Adults aside, Anvi's friends offered little support for her computing interests, not because they eschewed them but because, as she said, "None of my friends know anything about computing."

Anvi recalled her first years in high school as a low point in her life. Computing changed that. She remembered:

I had this really bad GPA 'til like sophomore year and then took Computer Science and then I loved it. And my GPA, it like instantly was better because I actually knew what I wanted to do with my life, so I was actually doing better.

She became close with her computer science teacher, who was her supporter thereafter.

Winning the AiC Award reinforced the confidence Anvi had begun to feel around computing. It also gave her connections with other like-minded girls, an opportunity to develop an app, entrée into a valuable internship, entrance to 
the Grace Hopper conference, and more, as the following excerpt shows:

I've talked to so many people...[NCWIT] has definitely helped me do that ... I was at a Community school so if I were to forward my resume to anyone it would have been hard to get that [Company name] internship, so definitely it really helped my technical career. And also it, it's a great booster to talk to other girls. I would have still continued doing computer science, but definitely NCWIT has given me so much opportunities that I wouldn't have gotten if I wasn't a part of it.

Beyond her own sense of computing self-efficacy, critical to Anvi's persistence in computing were having a caring computer science teacher who took a personal interest in her and the Aspirations Award win. She recalled:

When I got the NCWIT certificate I gave it to [my teacher], she hung it. She still has it on her wall. I feel like if she wouldn't have told me that I'm good enough, then I guess I would have never believed that I was. You know you need somebody to tell you you're good enough.

Anvi was majoring in computer science at a four-year university when we spoke with her. Her profile exemplifies the situation of many women who, without the one caring computer science teacher and without some network like the AiC Award winner community, may not end up persisting. Anvi did not have any more exposure to computing over time than Sophia (Profile 2) had, but winning the Award opened up a world for her that she would not have known about otherwise.

Stephanie. An Asian-American woman, Stephanie applied for but did not win the AiC Award in high school. Her real interest in CS actually didn't come until after college: "When I came into college I knew that I was going to be a neuroscience major, and I also knew that computer science was useful for conducting research. So I decided to take a couple of computer science classes, and it turned out that I really, really enjoyed them." Computing appealed to Stephanie because, as she said, it "is very math based...it clicks with me." She added, "It's very applicable to any field I might want to do in the future."

Stephanie felt that her interest in STEM was influenced by her Asian upbringing:

I think Asian parents have a tendency to want their children to do math and science and engineering, like work in STEM fields. At least for my family, it's because my dad does math and sciences, and so he obviously wants to project that onto me. And I know a lot of my other Asian friends have parents who are engineers or scientists.

Despite her interest, her high math self-efficacy (she was president of the math club in high school), and her familial encouragement, Stephanie encountered obstacles. She recalled a biased mentor she and a male partner had shared in a tech internship, saying that in their weekly meetings, he would:

usually... direct most of the questions to my partner, even if it was about a part that I worked on. And so I would have to, like, try to fit, I would try to edge my way in to answer the question because he was directing it at my partner. But it was, like, I knew the answer to the question 'cause I was working on it!

She said she didn't know what to do about it: "I wasn't really sure [laughs] how to deal with it. I just kind of would, like, he would [pause] ... I think usually my partner would look at me and then I would say something."

So while her family and her cultural background was a supportive factor in some ways for her pursuit of computing, she noted that she had to unlearn some other traits she was praised for as a child:

I'm from an Asian family and I remember as a child people would tell me that I was obedient if I didn't say much.... And I think that [pause] just subconsciously I thought that it would be good to be quiet.

She mentioned that during one internship, she was part of a "Lean In" group with other female interns, where they generally talked about "feeling and looking more confident when talking to male colleagues."

When discussing her college experiences, though, Stephanie described a very supportive environment. She said:

Another reason that I'm doing more computer science now is 'cause at [elite university] I've met a lot of close friends who are insanely good at computer science...I'm surrounded by all these amazing people. And it kind of influenced me to do more computer science.... Most of my male friends are either math or computer science majors, and most of my female friends are bioengineering.

When asked if she had a Lean In group in college like she participated in during her internship, she replied, "I think that the [university] community is in general very supportive of women and so we haven't felt the need to have a special group."

Stephanie's opportunity to attend college at her STEMfocused university not only brought with it a peer community who shared a STEM identity, but a specific computing community she aspired to be part of. Her experiences with a supportive male partner in her internship and a supportive female peer group in a different internship helped her navigate what could have been very discouraging experiences. Unlike Sophia (Profile 2), Stephanie came to understand how to integrate her academic interests and how to best position herself in the future job market. As she said, "I think it's very applicable to any field I might want to do in the future. Like whether or not I want to do, I guess, software engineering in industry or academic research, et cetera, I think computer science is pretty applicable." But her path was not nearly as unencumbered as Joan's (Profile 1).

The final profile below underscores how redundant discouraging experiences may at least temporarily be mitigated by an actively supportive peer community.

Martha. A White high-school student, Martha repeatedly applied for the AiC award and didn't win. She reflected:

I guess it wasn't really particularly discouraging until like senior year when I realized... basically everyone in my 
school who has applied has gotten some sort of nomination or something. And I find that very strange because I think my year, only me and my other friend who was on the robotics team applied. And she got it and I didn't. I was like, whatever. But since then it's been four or five girls!

She also encountered many stereotypes about what girls could do in computing, some of which she initially seemed to internalize. Martha reflected, "Especially when I was younger, I was a lot more discouraged about that because I thought, like my brother, he's my twin brother actually, we grew up in the same exact household, like we did all the same exact things, but he just can act like he knows a ton about computers. I probably know just as much as him but, at first I was like just leave all the computer stuff to my brother because he can figure it out."

Possibly because of her experiences at home, she felt that boys have a competitive edge, partly because of attitude:

I can feel frustrated about, like my own experiences, like a lot of the guys, I just, I don't even think they're necessarily more experienced or knowledgeable -- but they act like they are...I have no idea where some of the guys get their experience and stuff, so I don't know if it's just because, like, people are more likely to offer to show a guy something rather than a girl. Or, I don't know, because they just randomly know all this stuff.

Of the girlfriends that she started computing with, she said, "[They] end up kind of backing off and being like, 'Oh, I'll do just the web design." "Although Martha started in a place similar to her friends, her robotics experience proved pivotal. ,

I think my freshman year, I actually joined the robotics team because I wanted to do art and stuff. I joined for the 3D animation part, and then I got stuffed into the more technical parts like helping out with the robot.... [At first] I wouldn't touch the robot, I was scared to, I thought I'd break it. My senior year, I was the team captain and so there was obviously a large shift. [Now] I want to know [the very technical parts], I want to understand it."

She found support from boys on her robotics team:

It's actually great 'cause I've built a friend group, through my robotics team, a bunch of guys who are just totally willing to show me... They'll really teach anyone because that's just the sort of people they are. That's pretty great.

These friends also encouraged her to take AP CS, which Martha described as "the coolest class I've taken in all of high school."

When we spoke with her, Martha was planning to attend college and major in computer science, but without a supportive parent or teacher, and other encouragement once in college via peers or professors, she may not end up continuing through to a computing college degree or career. Her frustration with gender stereotyping coupled with her relative lack of experience in computer science may interfere with the identity she is forging for herself as someone who "does computing."

\section{DISCUSSION}

Those women in our sample who are persisting in computing had (a) an early reinforced computing identity, (b) their own supportive computing communities at home or in school, and/or (c) found path-changing support in the AiC Award community. Joan (Profile 1) had both the preparatory privilege and community and family support that set her up for success in her computing endeavors. Not once did she question whether she belonged in computing or doubt her computing identity. That she would not persist in computing did not seem to be a consideration. Both Anvi (Profile 3) and Martha (Profile 5) lacked the breadth of support that Joan had. But Anvi found the necessary encouragement through her teacher, which was then reinforced in multiple ways by being inducted into the AiC community. As a nonwinner, Martha (Profile 5) has found support in her high school friend group, but she may lose that community support as she moves forward into college.

Sophia (Profile 2) and Stephanie (Profile 4) both lacked early experiences that might have developed into a more solid computing identity, and prior to college, neither had access to much of a computing community. As nonwinners, neither young woman benefited from the robust support and community that $\mathrm{AiC}$ Award winners had. Nonetheless, Stephanie found her way to computing by being able to integrate computing into her research identity; the computing aspect of her self was further reinforced when she went to an elite, STEM-focused university. In contrast, Sophia lacked the breadth of experience and exposure to different ways that a computing identity could be expressed. She remained unable to figure out how to merge computing and animal sciences. Coupled with an inability to see how she could gainfully do computing professionally in her home community, Sophia opted to pursue another path.

Any one of these factors - early experiences that reinforce a computing identity, one's own locally-grown supportive community, or the AiC Award community-alone does not seem to be sufficient to keep a woman in computing, despite early interest. Rather, our data as a whole suggest that it is the bundling of several mutually reinforcing supportive factors that separate those who persist from those who do not persist.

In sum, our data suggest that the multiple supportive factors that contribute to women intending to pursue, or actually pursuing, computing include having:

- $\quad$ sufficient exposure to learn computing skills, whether in school or out of school

- $\quad$ sufficient community support, including teachers, parents, and peers

- $\quad$ respect and encouragement from other individuals in their computing journey.

Those women who lacked these redundant supports, women like Sophia, were much more likely to not pursue their initial interest in computing, even if they did not perceive themselves as having been turned off to computing or did not recognize that they lacked a sufficient variety of external supportive factors. Indeed, women's feeling of belonging (or 
not) in computing was influenced by many external, community factors in ways they themselves did not even realize.

To summarize, a recurrent theme we see in the data is that access to opportunities and a supportive environment correspond with high self-efficacy in computing and set the stage for developing a robust computing identity. Our data suggest that it is the combination of cumulative computing experiences, nurturing of computing self-efficacy, and having a community of support that together serve to develop and then reinforce a computing identity, i.e., "I am someone who does computing, and I belong in this field." Whether the community support comes via a parent, a teacher, a robotics coach, a group of girls, or a group of boys, community provides young women the backing necessary to navigate through barriers. Community may also include role models that demonstrate how young women might use computing in their own careers and how it will fit in with their other interests or talents. Lastly, a community that supports women in computing literally connects women with myriad tangible opportunities that then become a self-reinforcing cycle of exposure and experience, as we saw particularly with the winners of the National Aspirations in Computing Award.

\section{A. Future Research}

We will continue to examine our interview and focus group data for a better understanding of the socio-cultural and structural supports for those women who did persist in computing despite not having the NCWIT Award to buoy them. What were their supports, and how did these supports influence the women's paths? We are especially interested in looking at the role that out-of-school time activities such as robotics, afterschool and summer computing clubs, hack-athons, and internships play in young women's trajectories. These types of activities seem particularly powerful for many of the young women with whom we spoke. We will also more closely examine inhibiting factors for those winners and nonwinners who did not persist in computing or engineering, all the while testing our hypothesis that together community and cumulative support mediate the negative effects of entering a sometimes hostile school or work environment.

To this point, observation of the Facebook group the AiC Award winners can join suggests that the supports offered by this group may influence some women's persistence in computing. In the next year, we plan to analyze the conversations in this group to learn more about how a "community" or "cohort effect" may influence women's decisions about computing. We will be looking for what supports and barriers the Award winners have encountered and how they negotiated their way through to resolution.

In addition, in 2015-16, we fielded the second survey with all of the women in our database, i.e., those who had expressed interest in computing by registering on the $\mathrm{AiC}$ website or applying to the AiC Award between 2007-2013. In the coming months, we will compare data from our first and second surveys to see if there were any attitudinal changes over time and to monitor the women's persistence in the field. We will also compare and contrast analyses from our quantitative and qualitative datasets to try to better understand what influences interest in persisting in computing.

Ultimately, findings from this research project will deepen the discipline's understanding of what factors and environments encourage and discourage women's persistence in computing, and how these factors interact with one another. These insights can, in turn, inform recruitment and teaching practices in computing for both high school and college instructors.

\section{ACKNOWLEDGMENTS}

This research is supported by the National Science Foundation under CNS 1441071 and CNS 0813956. Any opinions, findings, and conclusions or recommendations expressed in this paper are those of the author(s) and do not necessarily reflect the views of the National Science Foundation.

\section{REFERENCES}

[1] M. A. Kanny, L. J. Sax, and T. A. Riggers-Piehl. (2014). Investigating forty years of STEM research: How explanations for the gender gap have evolved over time. Journal of Women and Minorities in Science and Engineering, 20(2).

[2] J. Margolis, R. Estrella, J. Goode, J. J. Holme, and K. Nao. (2008). Stuck in the shallow end: Education, race, and computing. Cambridge, MA: MIT.

[3] J. Margolis and A. Fisher, Unlocking the Clubhouse: Women in Computing, Cambridge, MA: MIT Press, 2002.

[4] J. Goode. (2010). The digital identity divide: how technology knowledge impacts college students. New media \& society, 12(3), 497-513.

[5] J. S. Light. (2001). Rethinking the Digital Divide. Harvard Educational Review, 71(4), 709-733.

[6] N. Selwyn. (2004). The information aged: A qualitative study of older adults' use of information and communications technology. Journal of Aging studies,18(4), 369-384.

[7] J. R.Valadez and R. Duran. (2007). Redefining the digital divide: Beyond access to computers and the Internet. The High School Journal, 90(3), 31-44.

[8] M. Warschauer, M. Knobel and L. Stone. (2004). Technology and Equity in Schooling: Deconstructing the Digital Divide.Educational Policy, 18(4), 562-588. http://doi.org/10.1177/089590480426649

[9] S. Cheryan, A. Master and A. N. Meltzoff. (2015). Cultural stereotypes as gatekeepers: increasing girls' interest in computer science and engineering by diversifying stereotypes. Frontiers in Psychology, 6. Retrieved fromhttp://www.ncbi.nlm.nih.gov/pmc/articles/PMC4323745/

[10] Google. (2014). Women Who Choose Computer Science--What Really Matters: The Critical Role of Encouragement and Exposure.

[11] R. D. Robnett and C. Leaper. (2012). "Friendship Groups, Personal Motivations, and Gender in Relation to High School Students' STEM Career Interest." Journal of Research on Adolescence 23(4): 652-64.

[12] J. Goode, R. Estrella and J. Margolis. (2006). "Lost in translation: Gender in high school computer science." In J. Cohoon, and W. Aspray (Eds.)., Women and Information Technology: Research on Underrepresentation. MIT Press.

[13] M. Cozza. (2011). Bridging gender gaps, networking in computer Science. Gender, Technology and Development, 15(2), 319-337.

[14] J. Jenson, S. de Castell, and M. Bryson. (2003). "Girl talk": Gender, equity, and identitydiscourses in a school-based computer culture. Women's Studies International Forum, 26(6), 561-573.

[15] P. Moorman and E. Johnson. (2003). Still a stranger here: attitudes among secondary school students towards computer science. ITiCSE '03 Proceedings of the 8th annual conference on Innovation and technology in computer science education, 193-197 
[16] J. Teague. (2002). Women in Computing: What brings them to it, what keeps them in it? SIGCSE '02 Proceedings of the 33rd SIGCSE technical symposium on computer science education, 147-158.

[17] L. J. Barker and W. Aspray. (2006). The state of research on girls and IT. In J.M. Cohoon \& W. Aspray (Eds.), Women and Information Technology: Research on Underrepresentation, pp. 3-54). Cambridge: MIT Press.

[18] P. S. Meszaros, E. Creamer and L. Soyoung. (2009). Understanding the role of parental support for IT career decision making using the theory of self-authorship. International Journal of Consumer Studies, 33(4), 392-395.

[19] L. L. Espinosa. (2011). Pipelines and Pathways: Women of Color in Undergraduate STEM Majors and the College Experiences that Contribute to Persistence.Harvard Educational Review, 81(2), 209-240.

[20] H. B., Carlone and A. Johnson. (2007). Understanding the Science Experiences of Successful Women of Color: Science Identity as an Analytic Lens. Journal of Research in Science Teaching, 44(8), 11871218. http://doi.org/10.1002/tea.20237

[21] L. J. Barker, E. Snow, K. Garvin-Doxas and T. Weston. (2006). Recruiting middle school girls in IT: Data on girls' perceptions and experiences from a mixed-demographic group. In J. Cohoon \& W. Aspray (Eds)., Women and Information Technology: Research on Underrepresentation. Cambridge: MIT Press.

[22] S. Cheryan and V. C. Plaut. (2010). Explaining underrepresentation: A theory of precluded interest. Sex Roles, 63(7-8), 475-488.
[23] Barker, L. J., \& Aspray, W. (2006). The state of research on girls and IT. In J.M. Cohoon \& W. Aspray (Eds.), Women and Information Technology: Research on Underrepresentation, (pp. 3-54). Cambridge: MIT Press.

[24] J. C. Blickenstaff. (2005). Women and science careers: Leaky pipeline or gender filter? Gender and Education, 17(4), 369-386.

[25] J. Margolis, R. Estrella, J. Goode, J. J. Holme, and K. Nao. (2008). Stuck in the shallow end: Education, race, and computing. Cambridge, MA: MIT.

[26] M. M. Voyles, S. M. Haller, and T. V. Fossum. (2007). Teacher responses to student gender differences. SIGCSE, 39(3), 226-230.

[27] M. Ong, C. Wright, L. L. Espinosa, and G. Orfield. (2011). Inside the Double Bind: A Synthesis of Empirical Research on Undergraduate and Graduate Women of Color in Science, Technology, Engineering, and Mathematics. Harvard Educational Review, 81(2), 172-208.

[28] R. W. Lent, S. D. Brown, and G. Hackett. (2000). Contextual supports and barriers to career choice: A social cognitive analysis. Journal of counseling psychology, 47(1), 36.

[29] M. Q. Patton. (1990). Qualitative evaluation and research methods $\left(2^{\text {nd }}\right.$ Ed.). Newbury Park: Sage Publications.

[30] J. W. Creswell. (1998). Qualitative inquiry and research design: Choosing amoung five traditions. Newbury Park: Sage Publications.

[31] B. Glaser and A. Strauss. (1967). The discovery of grounded theory. Chicago: Aldine. 